\title{
Article \\ Influence of Epilepsy on the Quality of Life of Patients with Brain Tumors
}

\author{
Stanisław Krajewski ${ }^{1,2, *}$, Magdalena Wójcik ${ }^{1}$, Marek Harat ${ }^{2,3}$ and Jacek Furtak ${ }^{2,4}$ \\ 1 Department of Physiotherapy, University of Bydgoszcz, 85-059 Bydgoszcz, Poland; kondycja@gmail.com \\ 2 Department of Neurosurgery, 10th Military Research Hospital, 85-681 Bydgoszcz, Poland; \\ marek.harat@10wsk.mil.pl (M.H.); jacek.furtak2019@gmail.com (J.F.) \\ 3 Department of Neurosurgery and Neurology, Collegium Medicum in Bydgoszcz, \\ Nicolaus Copernicus University, 87-100 Torun, Poland \\ 4 Department of Neurooncology and Radiosurgery, Franciszek Łukaszczyk Oncology Center, \\ 85-796 Bydgoszcz, Poland \\ * Correspondence: krajewskirehabilitacja@wp.pl
}

Citation: Krajewski, S.; Wójcik, M.; Harat, M.; Furtak, J. Influence of Epilepsy on the Quality of Life of Patients with Brain Tumors. Int. J. Environ. Res. Public Health 2021, 18 6390. https://doi.org/10.3390/ ijerph18126390

Academic Editor: Paul B. Tchounwou

Received: 10 May 2021

Accepted: 8 June 2021

Published: 12 June 2021

Publisher's Note: MDPI stays neutral with regard to jurisdictional claims in published maps and institutional affiliations.

Copyright: (c) 2021 by the authors. Licensee MDPI, Basel, Switzerland. This article is an open access article distributed under the terms and conditions of the Creative Commons Attribution (CC BY) license (https:/ / creativecommons.org/licenses/by/ $4.0 /)$.

\begin{abstract}
Epilepsy is a common consequence of brain tumors, occurring in 35 to $75 \%$ of cases. Here we evaluated the influence of epilepsy on the quality of life $(\mathrm{QoL})$ of patients with malignant brain tumors (primary and metastatic) and assessed which areas of function are most affected by epilepsy and brain tumors. Sixty patients undergoing brain tumor surgery at the Neurosurgery Clinic of the 10th Military Research Hospital, Bydgoszcz, Poland (30 with epilepsy and 30 without epilepsy) were studied. Relationships between categorical variables were determined with Pearson's chi-squared test, while continuous data were analyzed with the Mann-Whitney U-test. A $p$ value $<0.05$ was considered statistically significant. A multiple regression model was used for multivariate analysis of QoL. Patients with epilepsy more frequently reported memory disorders as a problem in their daily life. There were trends towards greater impairments in social, professional, and family life, sports and recreational activities, and daily physical activities in brain tumor patients with epilepsy rather than those without epilepsy. Higher frequency and generalized seizures significantly and adversely influenced the ability of patients to leave home and drive vehicles, but a proportion of patients with frequent, generalized seizures continued to drive regardless. Patients with generalized seizures considered the adverse effects of taking medicines as significantly disruptive. Memory disorders significantly affect the QoL of patients with epilepsy, and the importance of stopping driving must be emphasized by all healthcare professionals.
\end{abstract}

Keywords: brain tumor; epilepsy; quality of life; driving; memory

\section{Introduction}

Primary brain tumors account for 1-2\% of all neoplasms, affecting 5-23 people per 100,000 every year and representing $2-2.5 \%$ of all cancer deaths. Although demographic data vary, the annual age-adjusted incidence rate of primary brain tumors in the US is 24.8 for women and 20.3 for men, and the disease is more common in Europe and North America than in South-East Asia and Central and South Africa due to a mixture of environmental (i.e., industrialization) and ethnic and genetic factors. About two-thirds of primary brain tumors are benign, half of which are meningiomas. Of the malignant tumors, about $80 \%$ are gliomas, over half of which are highly malignant glioblastomas (GBM) [1-4].

Data on the incidence of metastases to the brain also vary, but the US National Brain Tumor Society report at least twice as many secondary brain cancer diagnoses than primary brain cancer diagnoses each year, although there are reports of 10-times more secondary than primary diagnoses. Regardless, brain metastases are common, affecting 10-30\% of patients with cancer and most commonly arising from primary lung (30-40\%), breast (5-19\%), skin (melanoma; $7-10 \%)$, and colon and rectum $(7 \%)$ cancers $[1,3,5-8]$. 
Epilepsy affects about $35-70 \%$ of patients with a brain tumor and often occurs as an early or first clinical symptom. Seizures most often occur in patients with glioneuronal tumors $(70-80 \%)$, especially those with fronto-temporal and insular lesions. Epilepsy occurs in $60-70 \%$ of patients with gliomas [9-13]. As early as the 1990s, early-onset epilepsy in patients with both high- and low-grade gliomas was found to be a positive predictor of overall survival [14-18]. The type of epileptic seizures and their frequency and prognosis depend on the type, localization, and size of tumor. Seizures are more common in patients with slow-growing, poorly differentiated tumors, but epileptogenesis may also be associated with certain genetic disorders [9,11-13].

Epilepsy is rarer in patients with metastatic lesions (15-25\%), with melanoma metastases conferring the greatest risk of seizure (11-33\% [6]) followed by lung metastases $(12.5-20 \%)$. In terms of mechanism, metastatic tumors tend to be more circumscribed than infiltrating primary tumors, which may explain the lower frequency of seizures in metastatic patients. Furthermore, metastases cause local microcircuiting disorders resulting in ischemic areas and epilepsy, while slow-growing gliomas result in denervation hypersensitivity as the epileptogenic mode of action [18]. Patients with metastatic tumors of the central nervous system usually quickly deteriorate and die, and the life expectancy is usually less than six months. Patients with primary tumors usually fare slightly better and live a few months longer $[8,19]$.

In one comparison of the quality of life (QoL) of patients with primary tumors and metastases $(n=1483)$, patients with primary tumors had significantly worse cognitive function than those with metastases [19]. By contrast, another study $(n=1808)$ showed that patients with primary tumors seem to have better social and functional wellbeing then those with metastatic brain tumors [20]. In both of these studies, the overall QoL scale results and some QoL subdomains (physical and emotional wellbeing, role functioning, and some symptoms such as fatigue, nausea/vomiting, pain, insomnia, and diarrhea) were not significantly different between groups, perhaps due to significant differences in group sizes and heterogeneity of the study populations $[19,20]$.

Nevertheless, patients with brain tumors can suffer from cognitive dysfunction in their attention, memory, and concentration as well as emotional changes such as anxiety and depression. Furthermore, paresis or paralysis, visual and hearing disturbances, and/or aphasia may also develop secondary to brain tumors. While all these symptoms can deteriorate a patient's QoL, epileptic seizures are generally regarded as having one of the greatest effects on QoL, even in the absence of a brain tumor [4,9-12,17,21-23]. Patients with brain tumors and epilepsy require multidisciplinary treatment, but the combined use of antiepileptic drugs (AEDs), cancer treatment (chemo- and radiotherapy), and auxiliary therapies exposes patients to drug interactions and adverse effects [11,12,24-31]. Together, the physical consequences of brain tumors, epilepsy, and complex treatment severely impact function in multiple domains including social and family relationships, employment and ability to work, activities of daily living, and all areas of physical activity [10-12,32-34]

QoL and health-related quality of life (HRQoL) are useful concepts not only for evaluating individual patients but also to guide clinical management to aid recovery. When brain tumors and epilepsy co-exist, it is important to determine the extent to which epilepsy and its associated disorders alter the QoL of a patient with brain cancer [12,22,35,36].

Here we evaluated the influence of epilepsy on the QoL of patients with brain tumors to establish the functional domains most impacted by epilepsy and brain tumors.

\section{Materials and Methods}

\subsection{Study Design}

This study was conducted between June and August 2019 at the Neurosurgery Clinic of the 10th Military Research Hospital, Bydgoszcz, Poland. Sixty patients with supratentorial brain tumors (including metastases) participated: 30 patients with brain tumors and epilepsy, and 30 patients with brain tumors but without epilepsy. The Ethics Committee of the Military Chamber of Physicians (no. 170/19) approved the study protocol. 
Participants completed a single self-administered questionnaire in four parts. The first and second parts were administered to all participants to gather demographic details, general information about their cancer, and QoL in the four weeks prior to the survey. Parts three and four were completed only by the study group and gathered information on epilepsy course and QoL influenced by epilepsy in the four weeks prior to the survey. The questionnaire contained both open- and closed-ended questions.

To evaluate the effect of epilepsy on the functioning of patients with brain tumors, study participants were also asked questions regarding their independence, physical activity, professional activity, social activity, and mental state:

Evaluation of independence: Questions were asked regarding: (i) help needed from other people to assist with tasks outside the house (shopping, administrative tasks, and nursery/school runs for children/grandchildren); (ii) disease influence on activities associated with self-care (preparing and eating meals, daily hygiene, and moving around at home); and (iii) limitations in activities associated with physical exercise necessary in daily life (going up or down the stairs, carrying heavy shopping, and carrying out more demanding household chores such as washing the windows and working in a garden). This section could score 4-14 points, where 4 denoted that the disease did not affect the evaluated aspects of the activity and 14 denoted the strongest effect.

Evaluation of physical activity: A total of 3-10 points for questions related to limitations to participating in or giving up sports activities, limitations to daily physical exercises, and becoming less active during leisure time.

Evaluation of professional activity: A total of 2-8 points for questions regarding limitations to professional activity and the quality of performed work, taking into account absence from work, breaks at work, number of working hours, and responsibilities.

Evaluation of social activity: A total of 5-14 points for questions regarding limitations to leaving home, limitations to driving a car, and limitations to social (social meetings) and family life.

Evaluation of mental state: A total of 2-6 points for questions regarding reductions in energy, the will to undertake daily activities, and problems with concentration, planning, and decision-making.

Therefore, the overall score ranged from 16 to 52 points. A score of 16 was considered an individual baseline for subjects in the pre-disease period, i.e., a score of 16 at the time of completing the questionnaire meant that the disease did not have any impact on the assessed aspects of the respondent's life. A score of 52 points was possible by selecting the lowest activity for all spheres of response assessed.

\subsection{Statistical Analysis}

To evaluate the influence of the disease(s) on QoL, the percentage reduction in analyzed aspects of QoL and in overall QoL, was calculated. Data were analyzed using Statistica v13.1 (StatSoft, Hamburg, Germany). Continuous data are presented as descriptive statistics, including mean and standard deviation (SD), while categorical data are presented as numbers and percentages. Relationships between categorical variables were determined with Pearson's chi-squared test, while continuous data were analyzed with the Mann-Whitney U-test. A $p$ value $<0.05$ was considered statistically significant. A multiple regression model was used for multivariate analysis of QoL.

\section{Results}

The demographic and clinical data of the study respondents are shown in Table 1. Twelve women and 18 men (aged $47.2 \pm 13.5$ [23-75 years]) had brain tumors and epilepsy, while 21 women and nine men (age $46.7 \pm 15.4$ [25-72 years]) had brain tumors alone. There was a significant difference in the number of men and women between the study and control groups $(p=0.020)$. The time from diagnosis of the brain tumor was over one year in $21(35.0 \%)$ patients, from six months to one year in $11(18.3 \%)$ patients, and less than 
six months in 28 (46.7\%) patients; the time from diagnosis did not differ between groups $(p=0.341)$.

Fifty patients $(83.3 \%)$ had primary brain cancer $(86.7 \%$ in the study group and $80.0 \%$ in the control group) and $10(16.7 \%)$ had metastases to the brain $(13.3 \%$ in the study group and $20 \%$ in the control group; not significantly different between study and control groups, $p=0.488)$ All patients underwent surgery. In $28(46.7 \%)$ patients, the procedure was preceded by a biopsy. Combined radio- and chemotherapy was given to $12(20.0 \%)$ patients, while five $(8.3 \%)$ patients underwent radiotherapy alone.

Table 1. Demographic and clinical data of the study participants.

\begin{tabular}{|c|c|c|c|c|c|c|c|c|}
\hline & & \multicolumn{2}{|c|}{ Study Group } & \multicolumn{2}{|c|}{ Control Group } & \multicolumn{2}{|c|}{ Total } & \multirow{2}{*}{$p$ Value * } \\
\hline & & $\mathbf{n}$ & $\%$ & $\mathbf{n}$ & $\%$ & $\mathbf{n}$ & $\%$ & \\
\hline \multirow{2}{*}{ Gender } & Female & 12 & 40.0 & 21 & 70.0 & 33 & 55.0 & \multirow{2}{*}{0.020} \\
\hline & Male & 18 & 60.0 & 9 & 30.0 & 27 & 45.0 & \\
\hline \multirow{3}{*}{$\begin{array}{l}\text { Time from } \\
\text { diagnosis }\end{array}$} & Over 1 year & 13 & 43.3 & 8 & 26.7 & 21 & 35.0 & \multirow{3}{*}{0.341} \\
\hline & 6 months to 1 year & 4 & 13.3 & 7 & 23.3 & 11 & 18.3 & \\
\hline & Less than 6 months & 13 & 43.3 & 15 & 50.0 & 28 & 46.7 & \\
\hline \multirow{2}{*}{ Type of cancer } & Primary & 26 & 86.7 & 24 & 80.0 & 50 & 83.3 & \multirow[b]{2}{*}{0.488} \\
\hline & Metastasis & 4 & 13.3 & 6 & 20.0 & 10 & 16.7 & \\
\hline \multirow{3}{*}{ Treatment } & Chemotherapy & 0 & 0.0 & 0 & 0.0 & 0 & 0.0 & 1.000 \\
\hline & Radiotherapy & 5 & 16.7 & 0 & 0.0 & 5 & 8.3 & 0.020 \\
\hline & $\begin{array}{l}\text { Both chemo- and } \\
\text { radiotherapy }\end{array}$ & 9 & 30.0 & 3 & 10.0 & 12 & 20.0 & 0.052 \\
\hline \multirow{2}{*}{\multicolumn{2}{|c|}{ Symptomatic treatment }} & 6 & 20.0 & 8 & 26.7 & 14 & 23.3 & 0.541 \\
\hline & & 14 & 46.7 & 14 & 46.7 & 28 & 46.7 & 1.0 \\
\hline \multicolumn{2}{|c|}{ Other chronic diseases } & 18 & 60.0 & 16 & 53.3 & 34 & 56.7 & 0.602 \\
\hline \multirow{2}{*}{\multicolumn{2}{|c|}{ 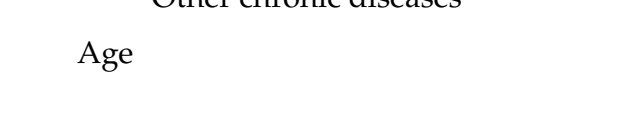 }} & \multirow{2}{*}{\multicolumn{2}{|c|}{$\begin{array}{c}\text { M; SD [range] } \\
47.2 \pm 13.5 \\
{[23-75]}\end{array}$}} & \multirow{2}{*}{\multicolumn{2}{|c|}{$\begin{array}{c}\mathrm{M} ; \mathrm{SD} \text { [range] } \\
46.7 \pm 15.44 \\
{[25-72]}\end{array}$}} & \multicolumn{2}{|c|}{ M; SD [range] } & \\
\hline & & & & & & 47. & $\begin{array}{l}4.37 \\
5]\end{array}$ & 0.790 \\
\hline
\end{tabular}

${ }^{*} p$ value-difference between study and control group.

With regard to specific symptoms other than seizures, only the frequency of memory disorders was different between groups, with memory disorders more common in brain tumor patients with epilepsy ( $p=0.044$; Table 2).

Overall QoL was compared based on gender, duration of disease, tumor type, and radio- and chemotherapy use. Although noting that there was only a small number of participants in each subgroup, the level of statistical significance between them has been waived. There were no statistically significant differences between groups for any of these variables (Table 3).

Table 2. First symptoms, frequency, and type of seizures.

\begin{tabular}{ccccc}
\hline Symptom & Study Group & Control Group & Total & $p$ Value * \\
\cline { 2 - 5 } & $\mathbf{n ~ ( \% )}$ & $\mathbf{n ~ ( \% )}$ & $\mathbf{n}(\mathbf{\%})$ \\
\hline Headaches & $3(10.0 \%)$ & $6(20.0 \%)$ & $9(15.0 \%)$ & 0.278 \\
Dizziness & $3(10.0 \%)$ & $6(20.0 \%)$ & $9(15.0 \%)$ & 0.278 \\
Consciousness disturbances & $1(3.3 \%)$ & $0(0 \%)$ & $1(1.7 \%)$ & 0.313 \\
Nausea, vomiting & $0(0 \%)$ & $1(3.3 \%)$ & $1(1.7 \%)$ & 0.313 \\
Fainting, loss of consciousness & $0(0 \%)$ & $2(6.7 \%)$ & $2(3.3 \%)$ & 0.150 \\
Most of the above & $1(3.3 \%)$ & $6(20.0 \%)$ & $7(11.7 \%)$ & 0.044 \\
Coordination disorders & $2(6.7 \%)$ & $1(3.3 \%)$ & $3(5.0 \%)$ & 0.553 \\
Balance disorders & $2(6.7 \%)$ & $310.0 \%)$ & $5(8.3 \%)$ & 0.640 \\
Somnolence & $1(3.3 \%)$ & $2(6.7 \%)$ & $3(5.0 \%)$ & 0.553 \\
Memory disorders & $6(20.0 \%)$ & $1(3.3 \%)$ & $7(11.7 \%)$ & 0.044 \\
Aphasia & $4(13.3 \%)$ & $4(13.3 \%)$ & $8(13.3 \%)$ & 1.000 \\
Face tingling & $0(0 \%)$ & $2(6.7 \%)$ & $2(3.3 \%)$ & 0.150 \\
\hline
\end{tabular}


Table 2. Cont.

\begin{tabular}{|c|c|c|c|c|c|}
\hline \multirow{2}{*}{\multicolumn{2}{|c|}{ Symptom }} & Study Group & Control Group & Total & $p$ Value * \\
\hline & & n (\%) & n (\%) & n (\%) & \\
\hline \multicolumn{2}{|c|}{ Muscle weakness } & $2(6.7 \%)$ & $2(6.7 \%)$ & $4(6.7 \%)$ & 1.000 \\
\hline \multicolumn{2}{|c|}{ Gait disturbance } & $0(0 \%)$ & $1(3.3 \%)$ & $1(1.7 \%)$ & 0.313 \\
\hline \multicolumn{2}{|c|}{ Blurred vision } & $0(0 \%)$ & $2(6.7 \%)$ & $2(3.3 \%)$ & 0.150 \\
\hline \multicolumn{2}{|c|}{ Foreign smells } & $0(0 \%)$ & $1(3.3 \%)$ & $1(1.7 \%)$ & 0.313 \\
\hline \multicolumn{2}{|c|}{ Bradykinesia } & $1(3.3 \%)$ & $0(0 \%)$ & $1(1.7 \%)$ & 0.313 \\
\hline \multicolumn{2}{|c|}{ Behavior changes } & $1(3.3 \%)$ & $0(0 \%)$ & $1(1.7 \%)$ & 0.313 \\
\hline \multicolumn{2}{|c|}{ No symptoms, tumor found by chance } & $0(0 \%)$ & $5(16.7 \%)$ & $5(8.3 \%)$ & 0.020 \\
\hline \multicolumn{2}{|c|}{ Epilepsy } & $30(100 \%)$ & - & - & \\
\hline \multicolumn{2}{|c|}{ Epilepsy as the first symptom } & $15(50 \%)$ & - & - & \\
\hline \multirow{2}{*}{ Seizure frequency } & $\begin{array}{c}\text { Few times per } \\
\text { week }\end{array}$ & $0(0 \%)$ & - & - & \\
\hline & $\begin{array}{c}\text { Few times per } \\
\text { month }\end{array}$ & $13(43.3 \%)$ & - & - & \\
\hline \multirow{3}{*}{ Seizure type } & Few times per year & $17(56.7 \%)$ & - & - & \\
\hline & Generalized & $11(36.7 \%)$ & - & - & \\
\hline & Focal & $19(63.3 \%)$ & - & - & \\
\hline
\end{tabular}

${ }^{*} p$ value-difference between study and control group.

Table 3. Overall quality of life (QoL) scores in patients with brain tumors with and without epilepsy.

\begin{tabular}{|c|c|c|c|c|}
\hline & & Study Group & Control Group & Total \\
\hline & & Mean, SD (n) & Mean, SD (n) & Mean, SD (n) \\
\hline \multirow{2}{*}{ Gender } & Female & $33.6 \pm 6.72(12)$ & $32.6 \pm 7.95(21)$ & $33.0 \pm 7.44(33)$ \\
\hline & Male & $34.8 \pm 6.90(18)$ & $33.0 \pm 9.96(9)$ & $\begin{array}{c}34.2 \pm 7.9(27) \\
p=0.530\end{array}$ \\
\hline \multirow{3}{*}{ Time from diagnosis } & Over 1 year & $35.2 \pm 6.43(13)$ & $33.4 \pm 9.02(8)$ & $34.5 \pm 7.35(21)$ \\
\hline & 6 months to 1 year & $34.8 \pm 4.03(4)$ & $36.6 \pm 7.72(7)$ & $35.9 \pm 6.44(11)$ \\
\hline & Less than 6 months & $35.2 \pm 6.42(13)$ & $30.6 \pm 8.27(15)$ & $\begin{array}{c}31.9 \pm 8.08(28) \\
p=0.173\end{array}$ \\
\hline \multirow[b]{2}{*}{ Type of cancer } & Primary & $33.5 \pm 6.35(26)$ & $32.1 \pm 9.21(24)$ & $32.9 \pm 7.80(50)$ \\
\hline & Metastasis & $39.5 \pm 7.85(4)$ & $35.2 \pm 3.60(6)$ & $\begin{array}{c}36.9 \pm 5.72(10) \\
p=0.126\end{array}$ \\
\hline & Chemo- and radiotherapy & $35.4 \pm 7.56(14)$ & $41.0 \pm 4.36(3)$ & $36.4 \pm 7.33(17)$ \\
\hline Treatment & No chemo- and radiotherapy & $33.4 \pm 6.03(16)$ & $31.8 \pm 8.31(27)$ & $\begin{array}{c}32.4 \pm 7.51(43) \\
p=0.386\end{array}$ \\
\hline
\end{tabular}

A multiple regression model significantly predicted QoL $(\mathrm{F}=4.39, p<0.044)$, with an $R^{2}$ of 0.131 . When corrected for age and treatment, gender was a significant predictor of QoL ( $\beta=0.362, p=0.045)$. Age, sex, and treatment were not independent predictors of QoL (Appendix A, Table A1). There were no statistically significant differences in QoL parameters nor overall QoL score between men and women (Appendix A, Table A2).

All brain tumor patients, regardless of epilepsy status, experienced deteriorated function in all QoL domains after diagnosis. The smallest deteriorations were in professional (43.3\% in the study group, $33.3 \%$ in the control group) and social (44.4\% and $37.7 \%$, respectively) activities, while largest deteriorations were for physical activity $(65.7 \%$ and $64.3 \%)$ and mental state $(62.5 \%$ and $52.5 \%)$. There were no significant differences in any QoL domain between groups, although higher values (worse status) were noted in the study group for four out of the five studied domains (Table 4). 
Table 4. Subgroup and overall QoL scores in patients with brain tumors with and without epilepsy.

\begin{tabular}{|c|c|c|c|c|}
\hline Parameter & Group & Mean, SD & Reduction in Parameter * & $p$ Value $* *$ \\
\hline \multirow{2}{*}{ Independence } & Study & $8.7 \pm 2.01$ & $47.0 \%$ & \multirow{2}{*}{0.817} \\
\hline & Control & $8.8 \pm 2.49$ & $48.0 \%$ & \\
\hline \multirow{2}{*}{ Physical activity } & Study & $7.6 \pm 1.94$ & $65.7 \%$ & \multirow[b]{2}{*}{0.970} \\
\hline & Control & $7.5 \pm 2.24$ & $64.3 \%$ & \\
\hline \multirow{2}{*}{ Professional activity } & Study & $4.6 \pm 2.64$ & $43.3 \%$ & \multirow[b]{2}{*}{0.448} \\
\hline & Control & $4.0 \pm 2.80$ & $33.3 \%$ & \\
\hline \multirow{2}{*}{ Social activity } & Study & $9.0 \pm 2.01$ & $44.4 \%$ & \multirow{2}{*}{0.367} \\
\hline & Control & $8.4 \pm 2.58$ & $37.7 \%$ & \\
\hline \multirow{2}{*}{ Mental state } & Study & $4.5 \pm 1.28$ & $62.5 \%$ & \multirow{2}{*}{0.275} \\
\hline & Control & $4.1 \pm 1.41$ & $52.5 \%$ & \\
\hline \multirow{2}{*}{ Overall assessment } & Study & $34.3 \pm 6.74$ & $50.8 \%$ & \multirow{2}{*}{0.579} \\
\hline & Control & $32.7 \pm 8.43$ & $46.4 \%$ & \\
\hline
\end{tabular}

* Note: Percentage changes (reductions in a given parameter) were calculated as follows: the minimum value (no effect) was subtracted from the maximum value of the indicator showing the strongest effect of the disease, e.g., for the overall score: $52-16=36$, where 36 is $100 \%$. The value of the parameter calculated for the study group was 34.3 so, compared to the pre-disease condition (16 points), it decreased by ( $34.3-16=18.3$ ), or $50.8 \%$. ${ }_{* *} p$ value-difference between study and control group.

To examine the impact of seizure severity on QoL, the study group (the 30 patients with epilepsy) was divided into patients with frequent seizures (several seizures a month; $n=13,43.3 \%$ ) and those with rare seizures (seizures occurring several times a year; $n=17$, $56.7 \%)$. Subjects experiencing more frequent seizures less left the home less often ( $p=0.034)$ and were less tolerant of antiepileptic drugs $(p=0.044)$ than those with less frequent seizures. There was no significant difference between the study and the control groups with respect to the frequency of leaving home. With respect to changes to driving a car, the study and the control groups did not differ, while patients with frequent seizures were significantly more likely to stop driving a car than those with rare epileptic seizures $(p=0.038$; Table 5).

Table 5. Influence of epileptic seizure frequency on selected aspects of functioning in patients with brain tumors.

\begin{tabular}{|c|c|c|c|c|c|}
\hline & & $\begin{array}{c}\text { Frequent } \\
\text { Seizures } \\
n=13\end{array}$ & $\begin{array}{c}\text { Rare } \\
\text { Seizures } \\
n=17\end{array}$ & $\begin{array}{l}\text { Total } \\
n=30\end{array}$ & $p$ Value * \\
\hline & & $n(\%)$ & $n(\%)$ & $n(\%)$ & \\
\hline \multirow{3}{*}{$\begin{array}{l}\text { Frequency of leaving } \\
\text { home }\end{array}$} & Not influenced by epilepsy & $4(30.8)$ & $8(47.1)$ & $12(40.0)$ & \multirow{3}{*}{$p=0.034$} \\
\hline & Moderate influence & $3(23.1)$ & $8(47.1)$ & $11(36.7)$ & \\
\hline & Significant limitation & $6(46.2)$ & $1(5.9)$ & $7(23.3)$ & \\
\hline Experienced adverse & Not experienced & $2(15.4)$ & $10(58.8)$ & $12(40.0)$ & \multirow{4}{*}{$p=0.044$} \\
\hline \multirow{3}{*}{$\begin{array}{c}\text { effects of antiepileptic } \\
\text { drugs }\end{array}$} & Experienced but coped with & $8(61.5)$ & $4(23.5)$ & $12(40.0)$ & \\
\hline & Experienced and unable to cope with & $3(23.1)$ & $3(17.7)$ & $6(20.0)$ & \\
\hline & Did not stop & $4(30.8)$ & $7(41.2)$ & $11(36.7)$ & \\
\hline \multirow[t]{2}{*}{ Driving a car } & Drives less frequently & 0 & $5(29.4)$ & $5(16.7)$ & \multirow[t]{2}{*}{$p=0.038$} \\
\hline & Ceased completely & $9(69.2)$ & $5(29.4)$ & $14(46.6)$ & \\
\hline
\end{tabular}

* $p$ value- difference between study and control group.

Among patients with epilepsy, 11 (36.7\%) had generalized seizures and $19(63.3 \%)$ patients had focal seizures. Patients with generalized seizures stopped driving vehicles significantly more often than those with focal seizures $(p=0.044$; Table 5), but over half $(53.4 \%)$ of patients with epilepsy did not stop driving, which included some patients with generalized seizures (Tables 5 and 6). 
Table 6. Influence of type of epileptic seizure on driving vehicles in patients with brain tumors.

\begin{tabular}{|c|c|c|c|c|}
\hline \multirow[t]{2}{*}{ Driving a Car } & $\begin{array}{c}\text { Generalized } \\
\text { Seizures } \\
n=11\end{array}$ & $\begin{array}{c}\text { Focal } \\
\text { Seizures } \\
n=19\end{array}$ & $\begin{array}{c}\text { Total } \\
n=30\end{array}$ & $p$ Value * \\
\hline & $n(\%)$ & $n(\%)$ & $n(\%)$ & \\
\hline Did not stop & $2(18.2)$ & $9(47.4)$ & $11(36.7)$ & \\
\hline Drives less frequently & $1(9.1)$ & $4(21.1)$ & $5(16.7)$ & $p=0.044$ \\
\hline Ceased completely & $8(72.7)$ & $6(31.6)$ & $14(46.6)$ & \\
\hline
\end{tabular}

${ }^{*} p$ value- difference between study and control group.

\section{Discussion}

In our experience, epilepsy is the most frequently observed symptom in patients with brain tumors, and it is often the first symptom (Table 2). This is consistent with epidemiological reports on brain tumors and epilepsy, which are reported to co-exist in $30-75 \%$ of cases [10,37-39] or even up to $90-100 \%$ in some reports [9]. Epilepsy as the first symptom of a brain tumor is reported to occur in $10-50 \%$ of cases [37-39]. According to Maschio et al., epileptic seizures are an initial symptom of brain tumors in $20-40 \%$ of patients, while $20-45 \%$ of patients develop epilepsy as the tumor progresses [12].

While QoL was universally affected by having a brain tumor, epilepsy did not further deteriorate the studied QoL domains. However, a patient's QoL also includes his or her mood, including complex facets of cognition and emotion. Even mild cognitive deficits may be of functional and psychosocial consequence to patients with brain tumors [31,40], and cognitive disorders are a frequent cause of complications associated with co-existent brain tumors and epilepsy [41]. Brain tumors alone pose a direct threat to cognitive function $[28,40]$, with memory and attention disorders observed in over $60 \%$ of patients with brain tumors [42]. Epilepsy and epileptic drugs are also reported to contribute to cognitive disorders, with memory and attention the most frequently reported side-effects of AEDs [43]. Aldenkamp et al. reported that the frequency of memory disorders in people with epilepsy was between $20 \%$ and $50 \%$, and some patients consider the cognitive consequences of epilepsy to be more exhausting than seizures [44].

The severity of cognitive impairment (including memory problems) in patients with brain tumors and concomitant epilepsy depends on many factors, including tumor size, location, histology, growth rate, patient age, cardiovascular risk, and germline and tumor genetic factors. In addition to local damage, brain tumors also cause global cognitive dysfunction by disrupting cognitive networks. Attention, memory, and executive function are most frequently affected $[28,45,46]$. Cognitive reserve (CR) also affects functioning, with individuals with high levels of $C R$ able to maintain daily functions despite the accumulation of significant neuropathology. As a result, patients with higher CR levels experience less of an effect from primary brain tumor-specific symptoms on QoL [47].

Surgical treatment, radiotherapy, or chemotherapy reduce tumor load and improve cognitive functioning but can also cause cognitive deficits [6,48]. For example, surgery most affects memory and executive function [49]. Radiotherapy can lead to a significant but usually transient cognitive disability in $50-90 \%$ of patients. Complications of radiotherapy include radiation necrosis and encephalopathy, which can result in dementia [50]. Learning, memory, information processing speed, and executive function disorders associated with chemotherapy have been described as "brain chemo" or "cancer-related cognitive impairment" [51-53].

Memory-related complaints are most common in patients with temporal epilepsy and can be divided into three types: (i) transient epileptic amnesia (recurrent episodes of amnesia); (ii) accelerated long-term forgetting (newly acquired memories fade over days to weeks); and (iii) remote memory impairment (loss of memories for personal or public facts or events from the distant past) [54]. Here, memory disorders were reported in 3.3\% of patients with brain tumors alone but in $20 \%$ of patients with co-existent epilepsy. Both 
epilepsy and AEDs can affect cognitive function and behavior $[25,28]$ and, in patients with brain tumors and epilepsy, the probability of delayed adverse effects of AEDs, such as cognitive disorders or depression, is higher than in patients with epilepsy not associated with a tumor. Although AEDs may not be the sole cause of these adverse effects, they may be a contributing factor [29]. According to the International Bureau for Epilepsy, over half of adult patients reported cognitive disorders caused by AEDs that affected work, leisure activities, and their family and social life [27].

Brain cancer affects the entire life of an affected patient. According to some studies, men are more prone to stress and to lowering QoL [55]. In another study, women tend to report worse QoL and more distress compared to males [56]. On the other hand, studies conducted on 236 patients operated on because of a brain tumor in Bydgoszcz, Poland did not show a statistically significant difference between gender and QoL [57]. Here we found gender as a significant predictor of QoL in multivariate analysis, but comparing mean values in the men's and women's groups, we found no differences.

Many patients are forced to give up their social roles [32,58], as do patients with epilepsy. The visible symptoms and consequences of treatment of brain tumors, such as paresis, speech disorders, and deteriorated appearance, together with a label of being "epileptic", may lead to frustration and adversely impact social and/or interpersonal relationships [12,32]. Indeed, in one study, stigmatization was reported to be the most difficult consequence of epilepsy [33]. Here, over half of patients with brain tumors and epilepsy limited their social activities and half of these patients limited their leaving home.

Patients with brain tumors and epilepsy are also particularly vulnerable to changes in their employment. The majority of people diagnosed with brain tumors stop working [59] and, similarly, epilepsy is a known barrier to starting and retaining a job [60]; indeed, nearly a quarter of both groups of patients studied here discontinued work. Although our patients reported that both epilepsy and brain tumors limited their professional functioning, their coexistence was not additive.

The severity of epilepsy appeared to influence its impact on the QoL of patients with brain tumors. Frequent epileptic seizures were reported in $43.3 \%$ of our patients and generalized seizures in $36.7 \%$ of subjects. Stavem et al. reported that patients not experiencing any epileptic seizures for six months had better results for all QoL parameters evaluated using the QOLIE-31 questionnaire compared to patients with one seizure a week or with daily seizures [61]. In patients hospitalized for epilepsy, generalized seizures contributed to a deterioration in QoL to a comparable extent to very frequent epileptic seizures and drug resistance [62]. When considering QoL in patients with epilepsy, limitations to driving are frequently listed as an adverse consequence of the disease [63]. Despite treatment, 30\% to $40 \%$ of patients with epilepsy do not have full seizure control, so patients with drugresistant epilepsy and frequent seizures, particularly generalized ones, are at increased risk of a car accident [26]. Rosińczuk-Tonderys et al. reported that $29 \%$ of driving patients with epilepsy felt that the disease made driving a car impossible but they still used a car, while $57 \%$ reported that their condition did not interfere with driving [64]. We found that 30.8\% of participants of our study with frequent seizures and $27.3 \%$ of patients with generalized seizures did not stop driving. In light of these results and the published literature, this result is concerning. In Poland, driving is regulated by the Regulations of the Minister of Health, 2019. When epilepsy is diagnosed, the neurologist informs the patient that he/she is not allowed to drive, and the patient signs the medical record to confirm that they have received and understand that information. A person with epilepsy may drive again after a six-month seizure-free period after the first seizure if he/she does not require AEDs or after two years (10 years for professional drivers) if AEDs are required. The neurologist does not inform the authorities about the disease, so the responsibility to adhere to the rules lies with the patient. Although driving vehicles with epilepsy is not a crime in Poland, there may be criminal sanctions if, as a result of an illness of which the person is aware, it leads to a road accident. The problem of driving with epilepsy and brain tumors is also exacerbated by the organic brain disease, which can impair decision-making by the 
patient. Therefore, during management, healthcare professionals should emphasize not only the importance of stopping driving but also the important role played by the family or caregivers in controlling the patient's activities. In this respect, one solution could be to obligate doctors to notify the relevant authorities to withdraw the driving license in these cases. Regardless of whether the patient suffers frequent or infrequent generalized or focal seizures, they should not drive a car both due to the side-effects of AEDs and the risk associated with experiencing a seizure when driving.

Here, $46.2 \%$ of patients significantly reduced their frequency leaving home due to frequent epileptic seizures, while $23.1 \%$ of subjects left home less often for this reason. Kobau et al. found that adults who had recently had a seizure reported significantly more days of limited activity compared to people with active epilepsy who had not suffered a recent seizure [35]. Eighty-five per cent of the studied patients with frequent epileptic seizures suffered from adverse effects from their drugs, and $23.1 \%$ of patients found that they could not cope with these adverse events. The QoL of patients with brain tumors and epilepsy represents the combined effects of the complex management of two diseases. Epilepsy accompanying brain tumors is frequently drug-resistant, complicating AED therapy and incurring a burden on the patient $[12,65]$. Adverse events from AEDs are reported to be more frequent in patients with epilepsy associated with brain tumors than in the population suffering from epilepsy alone [9]. Clinically, the adverse events from AEDs may be the most important factor determining QoL second to seizure frequency [30].

The presence of epilepsy is considered to be the most important risk factor for longterm disability in brain tumor patients $[11,12,23]$, impacting both mental and physical fitness and thus independence. Nearly all of our patients limited their daily physical activity due to epileptic seizures, the brain tumor, or their coexistence. Patient with epilepsy and suffering from recurring seizures are usually aware of their limitations, leading to anxiety and withdrawal from many physical activities $[32,66]$. Brain tumor patients similarly reduce their physical activity, and this negatively affects their QoL [67]. Nearly one-third of our patients with brain tumors and epilepsy played sports less often or less intensively than previously, while one third gave up sports altogether, resulting in a $65.7 \%$ and $64.3 \%$ reduction in physical activity in patients with and without epilepsy, respectively.

Patients with neurological deficits after brain tumor surgery are provided rehabilitation as soon as possible after the procedure [68-70]. However, given our results, rehabilitation may also be useful in people not manifesting neurological deficits, given the reported decline in physical activity due to cancer and epilepsy. While the objective effect of physiotherapy on many disease symptoms is small [71], mobilization through movement and exercise, in combination with psychological therapy, may positively influence areas of physical activity that are not permanently affected [72-74].

This study has several limitations. First, there was no assessment of QoL before disease onset, which may have resulted in overestimates of the impact of the disease on the assessed parameters. Second, we did not specifically analyze the tumor type, size, and location or detail the specific AEDs used by participants, and further research is necessary to establish the impact of these parameters on QoL in co-existent disease. Finally, while the study group of 60 patients is relatively small and the compared groups were heterogeneous in terms of gender and some of the first symptoms of the disease, but these parameters did not seem to have a major impact on the QoL parameters studied here.

\section{Conclusions}

Brain tumor patients with epilepsy were more likely to report memory disturbances than patients without epilepsy. While the differences between groups were not significant, both brain tumors and epilepsy resulted in deteriorations in QoL parameters, especially mental wellbeing and physical activities. Of concern, over half of patients with epilepsy and brain tumors, including some with frequent and generalized seizures, did not stop driving, and the serious risks and consequences of continuing to drive by people with epilepsy must be clearly emphasized by healthcare professionals. 
Author Contributions: Conceptualization, S.K., M.W.; methodology, S.K., M.W., project governance, S.K.; performance of surgeries in patients participating in the study, M.H., J.F.; data collection and analyses, M.W., S.K.; literature search and analysis, M.W., S.K.; writing-original draft preparation, M.W., S.K.; writing-review and editing, M.H., J.F.; supervision, M.H. All authors have read and agreed to the published version of the manuscript.

Funding: This research was funded by Stowarzyszenie Wspierania Klinicznego Oddziału Neurochirurgii Wojskowego Szpitala Klinicznego "STEREOTAKSJA"; 85-915 Bydgoszcz, ul. Powstańców Warszawy 5.

Institutional Review Board Statement: The Ethics Committee of the Military Chamber of Physicians (no. 170/19) approved the study protocol.

Informed Consent Statement: Informed consent was obtained from all subjects involved in the study. Written informed consent has been obtained from the patients to publish this paper.

Data Availability Statement: All data relevant to this study are reported within the manuscript.

Conflicts of Interest: The authors declare no conflict of interest.

\section{Appendix A}

Table A1. Multivariate analysis of quality of life (QoL).

\begin{tabular}{|c|c|c|c|c|c|}
\hline Dependent Variable & Independent Variables & BETA $(\beta)$ & SE & $\mathbf{t}$ & $p$ Value \\
\hline $\begin{array}{c}\text { Step 0 } \\
\text { QoL } \\
\mathrm{R}=0.39 ; \mathrm{R}^{2}=0.151 \\
\mathrm{~F}(3,27)=1.615 ; p=0.208\end{array}$ & $\begin{array}{c}\text { Age } \\
\text { Gender } \\
\text { Treatment }\end{array}$ & $\begin{array}{c}-0.052 \\
0.350 \\
-0.126\end{array}$ & $\begin{array}{l}0.127 \\
3.136 \\
2.002\end{array}$ & $\begin{array}{c}-0.255 \\
1.695 \\
-0.652\end{array}$ & $\begin{array}{l}0.800 \\
0.102 \\
0.520\end{array}$ \\
\hline $\begin{array}{c}\text { Step 1 } \\
\text { QoL } \\
\mathrm{R}=0.387 ; \mathrm{R}^{2}=0.150 \\
\mathrm{~F}(2,28)=2.473 ; p=0.102\end{array}$ & $\begin{array}{l}\text { Gender } \\
\text { Treatment }\end{array}$ & $\begin{array}{c}0.326 \\
-0.141\end{array}$ & $\begin{array}{l}0.181 \\
0.181\end{array}$ & $\begin{array}{c}1.806 \\
-0.779\end{array}$ & $\begin{array}{l}0.082 \\
0.442\end{array}$ \\
\hline $\begin{array}{c}\text { Step 2 } \\
\text { QoL } \\
\mathrm{R}=0.362 ; \mathrm{R}^{2}=0.101 \\
\mathrm{~F}(1,29)=4.398 ; p<0.044\end{array}$ & Gender & 0.363 & 0.173 & 2.097 & 0.045 \\
\hline
\end{tabular}

BETA ( $\beta$ ), standardized beta coefficient; $t$ values, Bt; SE, standard error.

Table A2. Subgroup and overall QoL scores in females and males with brain tumors with and without epilepsy.

\begin{tabular}{ccccc}
\hline Parameter & Group & Female Mean, SD & Male Mean, SD & $p$ Value \\
\hline \multirow{2}{*}{ Independence } & Study & $8.5 \pm 2.02$ & $8.8 \pm 2.05$ & 0.849 \\
& Control & $9.0 \pm 2.64$ & $8.6 \pm 2.24$ & 0.680 \\
Physical activity & Study & $7.8 \pm 2.09$ & $7.6 \pm 1.89$ & 0.176 \\
& Control & $7.7 \pm 2.67$ & $7.1 \pm 2.62$ & 0.934 \\
Professional activity & Study & $3.8 \pm 2.45$ & $5.1 \pm 2.68$ & 0.253 \\
& Control & $3.6 \pm 2.67$ & $4.8 \pm 3.07$ & 0.592 \\
Social activity & Study & $8.8 \pm 2.01$ & $9.1 \pm 2.05$ & 0.751 \\
\multirow{2}{*}{ Mental state } & Control & $8.4 \pm 2.67$ & $8.3 \pm 2.50$ & 0.773 \\
& Study & $4.8 \pm 1.11$ & $4.3 \pm 1.36$ & 0.751 \\
Overall assessment & Control & $4.0 \pm 1.41$ & $4.2 \pm 1.48$ & 0.967 \\
& Study & $33.6 \pm 6.72$ & $34.8 \pm 6.90$ & 0.641 \\
& Control & $32.6 \pm 7.95$ & $33.0 \pm 9.96$ & 0.741 \\
\hline
\end{tabular}

\section{References}

1. Barnholtz-Sloan, J.S.; Ostrom, Q.T.; Cote, D. Epidemiology of Brain Tumors. Neurol. Clin. 2018, 36, 395-419. [CrossRef]

2. Fuentes-Raspall, R.; Solans, M.; Roca-Barceló, A.; Vilardell, L.; Puigdemont, M.; Del Barco, S.; Comas, R.; García-Velasco, A.; Astudillo, A.; Carmona-Garcia, M.C.; et al. Descriptive epidemiology of primary malignant and non-malignant central nervous tumors in Spain: Results from the Girona Cancer Registry (1994-2013). Cancer Epidemiol. 2017, 50, 1-8. [CrossRef] [PubMed]

3. Gould, J.; McDonald, A. Breaking down brain cancer. Nature 2018, 561, 40-41. [CrossRef] [PubMed] 
4. DeAngelis, L.M.; Rosenfeld, S.S. General issues. In Neurology; Merritt Louis, E.D., Mayer, S.A., Rowland, L.P., Eds.; Urban \& Partner/Elsevier: Wrocław, Poland, 2012; Volume 2, pp. 411-418.

5. Bragstad, S.; Flatebø, M.; Natvig, G.K.; Eide, G.E.; Skeie, G.O.; Behbahani, M.; Pedersen, P.H.; Enger, P.Ø.; Skeie, B.S. Predictors of quality of life and survival following Gamma Knife surgery for lung cancer brain metastases: A prospective study. J. Neurosurg. 2018, 129, 71-83. [CrossRef] [PubMed]

6. Julie, D.A.R.; Ahmed, Z.; Karceski, S.C.; Pannullo, S.C.; Schwartz, T.H.; Parashar, B.; Wernicke, A.G. An overview of anti-epileptic therapy management of patients with malignant tumors of the brain undergoing radiation therapy. J. Seizure 2019, 70, 30-37. [CrossRef]

7. Ohgaki, H. Epidemiology of Brain Tumors. Cancer Epidemiol. 2009, 472, 323-342.

8. Lu-Emerson, C.; Eichler, A.F. Brain Metastases. Neuro Oncol. 2012, 18, 295-311. [CrossRef]

9. Van Breemen, M.S.M.; Wilms, E.B.; Vecht, C.J. Epilepsy in patients with brain tumours: Epidemiology, mechanisms, and management. Lancet Neurol. 2007, 6, 421-430. [CrossRef]

10. Goldstein, E.D.; Feyissa, A.M. Brain tumor related-epilepsy. Neurol. Neurochir. Pol. 2018, 52, 436-447. [CrossRef]

11. Maschio, M.; Dinapoli, L.; Zarabla, A.; Pompili, A.; Carapella, C.M.; Pace, A.; Giannarelli, D.; Occhipinti, E.; Jandolo, B. Outcome and tolerability of topiramate in brain tumor associated epilepsy. J. Neurooncol. 2008, 86, 61-70. [CrossRef]

12. Maschio, M. Brain Tumor-Related Epilepsy. Curr. Neuropharmacol. 2012, 10, 124-133. [CrossRef]

13. Englot, D.; Chang, E.; Vecht, C.J. Epilepsy and brain tumors. In Handbook of Clinical Neurology, 3rd ed.; Berger, M.S., Weller, M., Eds.; Elsevier B.V.: Amsterdam, The Netherlands, 2016; Volume 134, pp. 267-285.

14. Wegman-Ostrosky, T.; Reynoso-Noverón, N.; Mejía-Pérez, S.I.; Sánchez-Correa, T.E.; Alvarez-Gómez, R.M.; Vidal-Millán, S.; Cacho-Díaz, B.; Sánchez-Corona, J.; Herrera-Montalvo, L.A.; Corona-Vázquez, T. Clinical prognostic factors in adults with astrocytoma: Historic cohort. Clin. Neurol. Neurosurg. 2016, 146, 116-122. [CrossRef] [PubMed]

15. Cacho-Diaz, B.; San-Juan, D.; Salmeron, K.; Boyzo, C.; Lorenzana-Mendoza, N. Choice of antiepileptic drugs affects the outcome in cancer patients with seizures. Clin. Transl. Oncol. 2018, 20, 1571-1576. [CrossRef] [PubMed]

16. Benit, C.P.; Kerkhof, M.; Duran-Peña, A.; Vecht, C.J. Seizures as complications in cancer. In Cancer Neurology in Clinical Practice; Schiff, D., Arrillaga, I., Wen, P.Y., Eds.; Springer: Berlin/Heidelberg, Germany, 2017; pp. 153-169.

17. Rudà, R.; Trevisan, E.; Soffietti, R. Epilepsy and brain tumors. Curr. Opin. Oncol. 2010, 22, 611-620. [CrossRef]

18. Rudà, R.; Mo, F.; Pellerino, A. Epilepsy in brain metastasis: An emerging entity. Curr. Treat. Opt. Neurol. 2020, 22, 1-10. [CrossRef] [PubMed]

19. Chiu, N.; Chiu, L.; Zeng, L.; Zhang, L.; Popovic, M.; Chow, R.; Lam, H.; Poon, M.; Chow, E. Quality of life in patients with primary and metastatic brain cancer as reported in the literature using the EORTC QLQ-BN20 and QLQ-C30. Expert Rev. Pharmacoecon. Outcomes Res. 2012, 12, 831-837. [CrossRef]

20. Chiu, N.; Chiu, L.; Zeng, L.; Zhang, L.; Cella, D.; Popovic, M.; Chow, R.; Lam, H.; Poon, M.; Chow, E. Quality of Life in Patients with Primary and Metastatic Brain Tumors in the Literature as Assessed by the FACT-Br. World J. Oncol. 2012, 36, $280-285$. [CrossRef] [PubMed]

21. Kieszkowska-Grudny, A. Mental disorder in patients with cancer-Clinical approach. Oncol. Rev. 2013, 3, 119-128.

22. Kushner, D.S.; Amidei, C.H. Rehabilitation of motor dysfunction in primary brain tumor patients. Neuro Oncol. Pract. 2015, 2, 185-191. [CrossRef]

23. Taillibert, S.; Laigle-Donadey, F.; Sanson, M. Palliative care in patients with primary brain tumors. Curr. Opin. Oncol. 2004, 16, 587-592. [CrossRef]

24. Djibuti, M.; Shakarishvili, R. Influence of clinical, demographic and socioeconomic variables on quality of life in patients with epilepsy: Findings from Georgian study. J. Neurol. Neurosurg. Psychiatry 2003, 74, 570-573. [CrossRef] [PubMed]

25. Eddy, C.M.; Rickards, H.E.; Cavanna, A.E. The cognitive impact of antiepileptic drugs. Ther. Adv. Neurol. Disord. 2011, 4, 385-407. [CrossRef]

26. Hauser, A.; Josephson, S.A. Harrison. Neurology in clinical medicine. Polish edition. Czelej Publ. House Lub. 2008, $433-453$.

27. International Bureau for Epilepsy. Epilepsy and Cognitive Function Survey. Available online: https://www.ibe-epilepsy.org/ downloads/IBE\%20Epilepsy\%20and\%20CognitiveFunctionResults.pdf (accessed on 12 December 2020).

28. Coomans, M.B.; van der Linden, S.D.; Gehring, K.; Taphoorn, M.J.B. Treatment of cognitive deficits in brain tumour patientsCurrent state and future directions. Curr. Opin. Oncol. 2019, 31, 540-547. [CrossRef] [PubMed]

29. Gallagher, P.; Leach, J.P.; Grant, R. Time to focus on brain tumor-related epilepsy trials. Neurooncol. Pract. 2014, 1, 123-133. [CrossRef]

30. Perucca, P.; Carter, J.; Vahle, V.; Gilliam, F.G. Adverse antiepileptic drug effects: Towards a clinically and neurobiologically relevant taxonomy. Neurology 2009, 72, 1223-1229. [CrossRef]

31. Rossetti, A.O.; Stupp, R. Epilepsy in brain tumor patients. Curr. Opin. Neurol. 2010, 23, 603-609. [CrossRef]

32. Grabowska-Grzyb, A. Mental disorder in epilepsy. Pol. Przegl. Neurol. 2005, 2, 53-59. (In Polish)

33. Jacoby, A.; Snape, D.; Baker, G.A. Epilepsy and social identity: The stigma of a chronic neurological disorder. Lancet Neurol. 2005, 4, 171-178. [CrossRef]

34. Japp, A.; Gielen, G.H.; Becker, A.J. Recent aspects of classification and epidemiology of epilepsy associated tumors. Epilepsia 2013, 54 (Suppl. 9), 5-11. [CrossRef] [PubMed] 
35. Kobau, R.; Zahran, H.; Grant, D.; Thurman, D.J.; Price, P.H.; Zack, M.M. Prevalence of active epilepsy and health-related quality of life among adults with self-reported epilepsy in California: California Health Interview Survey, 2003. Epilepsia 2007, 48, 1904-1913. [CrossRef]

36. Zachwieja, J. Influence of selected factors on quality of life in epilepsy patients. Piel. Neurol. Neurochir. 2013, 2, 117-124. (In Polish)

37. Douw, L.; van Dellen, E.; de Groot, M.; Heimans, J.J.; Klein, M.; Stam, C.J.; Reijneveld, J.C. Epilepsy is related to theta band brain connectivity and network topology in brain tumor patients. BMC Neurosci. 2010, 11, 133-135. [CrossRef]

38. Jędrzejczak, J.; Mazurkiewicz-Bełdzińska, M. Epilepsy. Etiology. PZWL Warszawa 2018, 1, 1-15.

39. Podemski, R. Compendium of neurology. Via Med. Gdańsk 2011, 1, 385-395.

40. Shen, C.; Bao, W.M.; Yang, B.J.; Xie, R.; Cao, X.Y.; Luan, S.H.; Mao, Y. Cognitive deficits in patients with brain tumor. Chin. Med. J. 2012, 125, 2610-2617. [PubMed]

41. Gehring, K.; Aaronson, N.K.; Taphoorn, M.J.; Sitskoorn, M. Interventions for cognitive deficits in patients with a brain tumor: An update. Expert Rev. Anticancer. Ther. 2010, 10, 1779-1795. [CrossRef] [PubMed]

42. Tucha, O.; Smely, C.; Preier, M.; Lange, K.W. Cognitive deficits before treatment among patients with brain tumors. Neurosurgery 2000, 47, 324-334. [CrossRef]

43. Lodhi, S.; Agrawal, N. Neurocognitive problems in epilpsy. Adv. Psychiatr. Treat. 2012, 18, 232-240. [CrossRef]

44. Aldenkamp, A.P. Cognitive impairment in epilepsy: State of affairs and clinical relevance. Seizure 2006, 15, 219-220. [CrossRef]

45. Wefel, J.S.; Noll, K.R.; Scheurer, M.E. Neurocognitive functioning and genetic variation in patients with primary brain tumours. Lancet Onco. 2016, 17, 97-108. [CrossRef]

46. Kesler, S.R.; Noll, K.R.; Cahill, D.P.; Rao, G.; Wefel, J.S. The effect of IDH1 mutation on the structural connectome in malignant astrocytoma. J. Neurooncol. 2017, 565-574. [CrossRef] [PubMed]

47. Allen, D.; Hutchinson, D. Exploring cognitive reserve and compensatory behaviors used to maintain executive control function in adults with primary brain tumors. Univ. North Carol. Chapel Hill 2014. [CrossRef]

48. Day, J.; Gillespie, D.C.; Rooney, A.G.; Bulbeck, H.J.; Zienius, K.; Boele, F.; Grant, R. Neurocognitive deficits and neurocognitive rehabilitation in adult brain tumors. Curr. Treat. Options Neurol. 2016, 18, 22. [CrossRef]

49. Meskal, I.; Gehring, K.; Rutten, G.J.; Sitskoorn, M.M. Cognitive functioning in meningioma patients: A systematic review. J. Neurooncol. 2016, 128, 195-205. [CrossRef]

50. Makale, M.T.; McDonald, C.R.; Hattangadi-Gluth, J.A.; Kesari, S. Mechanisms of radiotherapy-associated cognitive disability in patients with brain tumours. Nat. Rev. Neurol. 2017, 13, 152-164. [CrossRef]

51. Wefel, J.; Kayl, A.; Meyers, C. Neuropsychological dysfunction associated with cancer and cancer therapies: A conceptual review of an emerging target. Br. J. Cancer 2004, 90, 1691-1696. [CrossRef]

52. Dietrich, J.; Monje, M.; Wefel, J.; Meyers, C. Clinical patterns and biological correlates of cognitive dysfunction associated with cancer therapy. Oncologist 2008, 13, 1285-1295. [CrossRef]

53. Janelsins, M.C.; Kesler, S.R.; Ahles, T.A.; Morrow, G.R. Prevalence, mechanisms, and management of cancer-related cognitive impairment. Int. Rev. Psychiatry 2014, 26, 102-113. [CrossRef]

54. Butler, C.R.; Zeman, A.Z. Recent insights into the impairment of memory in epilepsy: Transient epileptic amnesia, accelerated long-term forgetting and remote memory impairment. Brain 2008, 131, 2243-2263. [CrossRef]

55. Niemelä, A.; Koivukangas, J.; Herva, R.; Hakko, H.; Räsänen, P.; Mainio, A. Gender Difference in Quality of Life among Brain Tumor Survivors. J. Neurol. Neurophysiol. 2011, 2, 1-5. [CrossRef]

56. Suzuki, R.; Hirao, M.; Higuchi, T.; Takei, A.; Chang, C.; Fujimoto, T. Factors Influencing QOL in Patients with Brain Tumors Measured by Mood State after the Treatment: On Differences in Gender, Age, and Treatment modality. Jpn. J. Psychosom. Med. 2001, 41, 181-187.

57. Królikowska, A.; Jabłońska, R.; Antczak, A.; Haor, B.; Zieliński, P.; Harat, M. Selected Determinants of the Quality of Life after Surgical Treatment of Brain Tumors. J. Neurol. Neurosurg. Nurs. 2016, 5, 128-135.

58. Twardak, I.M.; Lisowska, A. Care of a patient with a metastatic brain tumor in the end-stage form of the disease-Case study. Piel. Zdr. Publ. 2018, 8, 325-331. (In Polish) [CrossRef]

59. Matérne, M.; Lundqvist, L.O.; Strandberg, T. Opportunities and barriers for successful return to work after acquired brain injury: A patient perspective. Work 2017, 56, 125-134. [CrossRef]

60. Staniszewska, A.; Sobiecki, M. Professional activity of epilepsy patients. Med. Pr. 2015, 66, 343-350. (In Polish) [CrossRef] [PubMed]

61. Stavem, K.; Loge, J.H.; Kaasa, S. Health status of people with epilepsy compared with a general reference population. Epilepsia 2000, 41, 85-90. [CrossRef]

62. Birbeck, G.L.; Hays, R.D.; Cui, X.P.; Vickrey, B.G. Seizure reduction and quality of life improvements in people with epilepsy. Epilepsia 2002, 43, 535-538. [CrossRef]

63. Fisher, R.S.; Vickrey, B.; Gibson, P. The impact of epilepsy from the patient's perspective I. Descriptions and subjective perceptions. Epilepsy Res. 2000, 41, 39-51. [CrossRef]

64. Rosińczuk-Tonderys, J.; Całkosiński, J.; Uchmanowicz, I.; Hulisz, K. Problems of daily functioning of epiletpsy patients. Probl. Piel. Via Med. 2010, 18, 371-378. (In Polish)

65. Pierzchała, K. Treatment-Resistent epileptic syndroms. Pol. Przegl. Neurol. 2010, 6 (Suppl. A), 42-43. (In Polish) 
66. Graczyk, A. Quality of Life of Patients in Palliative Care at Home and In-House Care and Satisfaction with Care in the Assessment of the Sick and Loved Ones. Ph.D. Thesis, Karol Marcinkowski Medical University, Poznań, Poland, 2012; pp. 19-29.

67. Cormie, P.; Nowak, A. The potential role of exercise in Neuro-Oncology. Front. Oncol. 2015, 5, 85. [CrossRef]

68. Kos, N.; Kos, B.; Benedicic, M. Early medical rehabilitation after neurosurgical treatment of malignant brain tummours in Slovenia. Radiol. Oncol. 2016, 50, 139-144. [CrossRef]

69. Bartolo, M.; Springhetti, I. Neurorehabilitation in Neuro-Oncology; Springer: New York, NY, USA, 2019; pp. $103-120$.

70. Oort, Q.; Dirven, L.; Taphoorn, M.J.B. Improving Patient's Functioning and Well-Being with Neurorehabilitation. In Neurorehabilitation in Neuro-Oncology; Springer: New York, NY, USA, 2019; pp. 195-210.

71. Kim, B.R.; Chun, M.H.; Han, E.Y.; Kim, D.K. Fatigue assessment and rehabilitation outcomes in patients with brain tumors. Support. Care Cancer 2012, 20, 805-812. [CrossRef] [PubMed]

72. Okamura, H. Importance of rehabilitation in cancer treatment and palliative medicine. Jpn. J. Clin. Oncol. 2011, 41, 733-738. [CrossRef]

73. Moroz, A.; Flanagan, S.R.; Zaretsky, H. Medical Aspects of Disability for the Rehabilitation Professional, 5th ed.; Springer: New York, NY, USA, 2016.

74. Ruden, E.; Reardon, D.A.; Coan, A.D.; Herndon, J.E., 2nd; Hornsby, W.E.; West, M.; Fels, D.R.; Desjardins, A.; Vredenburgh, J.J.; Waner, E.; et al. Exercise behavior, functional capacity, and survival in adults with malignant recurrent glioma. J. Clin. Oncol. 2011, 29, 2918-2923. [CrossRef] 